\title{
On nonexclusive membership in competing joint ventures
}

\author{
Jerry A. Hausman* \\ Gregory K. Leonard ${ }^{* *}$ \\ and
}

Jean Tirole ${ }^{* * *}$

\begin{abstract}
We evaluate the competitive and governance effects of "duality." Duality refers to the joint membership (e.g., by banks) in competing associations or joint ventures (e.g., Visa and MasterCard). We first show that the not-for-profit nature of the associations along with the usage-based fees they charge yield productive efficiency. We then analyze the impact of (i) membership exclusivity, when the associations remain not-for-profit, and (ii) the conversion into for-profit systems. We illustrate the results in the case of a doubledifferentiation model that is of independent interest. Finally, we discuss extensions to (i) endogenous system differentiation, and (ii) agency considerations
\end{abstract}

\section{Introduction}

- Overview. The credit card associations Visa and MasterCard are organized as not-for-profit joint ventures owned by their respective members. An interesting feature of their organization is that, since the mid-1970s, a member of Visa can also be a member of MasterCard. This feature is known as "member duality." Today, most issuers of Visa credit cards are also members of the MasterCard association and vice versa. Furthermore, there is "board duality" in that banks sitting on the board of one association usually issue both types of cards.

* Massachusetts Institute of Technology; jhausman@mit.edu.

** Lexecon Inc.; gleonard@lexecon.com.

*** Institut D'Economie Industrielle; tirole@cict.fr.

Useful discussions with and comments from Kyle Bagwell, Howard Chang, David Evans, Eric Maskin, Patrick Rey, Jean-Charles Rochet, and two anonymous referees are gratefully acknowledged. We thank Nina Tobio for excellent research assistance. We are grateful to Citicorp and Visa USA, Inc. for financial support for this research. The views expressed in this article, however, need not represent those of either institution.

Copyright (C) 2003, RAND. 


\section{2 / THE RAND JOURNAL OF ECONOMICS}

The credit card industry is but one illustration of a more general environment. Joint ventures and in particular not-for-profit joint ventures account for a nonnegligible fraction of economic activity (see Hansmann, 1996), and the scope of not-for-profit associations financed by usage charges will expand as the world becomes more networked and joint ventures occur more frequently (see our concluding section for potential applications of our work to busines-to-business (B2B) exchanges and to the financial sector).

An important question (and one that has already been posed in the credit card context $)^{1}$ arises in this environment: Should association members, and in particular members sitting on an association's board, be allowed to belong to multiple associations, or should they be required to have an exclusive relationship with a single association? A concern is that duality may have the anticompetitive effect of reducing the incentives of the associations to invest in cost-saving or quality-enhancing innovations. An innovation in one system would most likely lead it to gain market share at the expense of the other association. Because members also have an interest in the other assocation, the association might be less likely to undertake such an innovation than if duality were eliminated.

This article evaluates the competitive effects of duality. Section 2 sets up a general model; a concentrated upstream segment, consisting of two systems (e.g., Visa and MasterCard), supplies an input to a less concentrated downstream segment composed of users (e.g., issuers) who in turn sell to the final consumers. The systems are run as not-for-profit organizations and charge usage-based fees. We consider the cases of duality, where members of one association (including board members) can also join the other association, and exclusive membership, where members of one association are not permitted to join the other association.

Section 3 illustrates the model and its main assumptions in a framework that is of independent interest. In this "double-differentiation" framework, both systems and users are differentiated, and the impacts of the two forms of differentiation are additive. We characterize the equilibrium of this "double-decker" industry and show that the assumptions made for the general model are satisfied.

Section 4 investigates the associations' incentives for investment in innovation and demonstrates that the associations choose the economically efficient level of investment in innovation despite the existence of duality. The combination of the not-for-profit status and usage-based fees serves to eliminate the potential problem of the exercise of upstream market power by the associations. If the assocations were turned into for-profit organizations, they would have the incentive and the ability (given the barriers to entry into systems) to raise price above competitive levels, an outcome that would harm both users and final consumers. While a for-profit system would deny membership to users that would not increase its net revenue, the not-for-profit setup in contrast encourages free entry by users.

Finally, Section 5 discusses several extensions of the model and avenues for future research in the area. In particular it provides some first results on whether duality is likely to reduce or increase system differentiation and on the welfare implications thereof. This section also discusses how duality impacts the agency problem, an important issue in not-for-profit associations. The section concludes with a discussion of some alternative industries to which the theory can be applied.

1 The U.S. Department of Justice has filed a complaint against Visa and MasterCard, seeking among other things to eliminate board duality; that is, banks sitting on the board of an association would need to have an exclusive relationship with that association. 
$\square \quad$ Brief introduction to the credit card industry. In recent years, the number of payment methods available to consumers has grown substantially. ${ }^{2}$ Today, the alternatives include cash, checks, charge cards, credit cards, and ATM/debit cards. The share of card payments has grown over time and is expected to grow further as e-commerce becomes more important.

The major players in the Visa and MasterCard segment of the credit card industry are the issuers, the merchant acquirers, and the systems. The issuers offer credit cards to consumers. The merchant acquirers handle transaction processing for merchants. The systems are computer networks that handle the interaction between a merchant acquirer and issuer required for a credit card transaction to take place.

When a consumer uses a Visa credit card to pay a merchant, the merchant sends the credit card number to its acquirer. The acquirer accesses the Visa system and verifies the card number and the availability of credit with the card issuer. After verification, the acquirer pays the merchant the amount of the sale less the "merchant discount," the issuer pays the acquirer the amount of the sale less the "interchange fee" and "assessment," and the issuer charges and bills the consumer.

Over 6,000 entities issue credit cards. Concentration among issuers, as measured by the HHI, is quite low. Currently, the between-issuer differentiation in credit cards tends to be greater than the between-system differentiation.

Four major credit card systems currently exist. Visa and MasterCard are "open" systems in that they are associations of issuers and acquirers with open membership. American Express and Discover are "closed" systems in that the owner of the system is the only issuer of the associated credit cards.

The Visa and MasterCard associations are not-for-profit organizations. They are "owned" by their members and run by a management team with oversight by a board of directors consisting of members. The associations charge members fees to cover their costs. The bulk of the fee for a given member is set so as to be proportional to the member's usage of the system. The associations set the interchange fee, promote the system, and invest in system improvements. However, the elements of downstream competition, e.g., the choice of credit card characteristics and the merchant discount, are left to the member issuers and acquirers. Thus, the associations are examples of a production joint venture where the owners of the joint venture cooperate within the limits of the joint venture, but compete without restraint downstream.

As mentioned above, a member of Visa can be a member of MasterCard as well. The existence of this "duality" was not the result of an affirmative decision on the part of the Visa and MasterCard associations. Instead, duality came about through what might be termed an accident of history. In 1975, Visa's predecessor association sought to prevent duality, thereby keeping its membership separate from MasterCard's. However, as the result of an antitrust lawsuit filed against it (and the lack of support for exclusivity by the Department of Justice), Visa grudgingly allowed duality. Soon thereafter, many credit card issuers took advantage of duality to become members of both associations. Today, most Visa issuers are members of MasterCard and vice versa.

In the next section, we develop a model that incorporates the key features of the associations and issuers described above. We use the model to investigate whether the existence of duality reduces the incentives of the associations to invest in system improvements.

${ }^{2}$ See Evans and Schmalensee (1999) for a detailed description of the credit card industry and a historical perspective. 


\section{4 / THE RAND JOURNAL OF ECONOMICS}

\section{The model}

- Systems. For notational simplicity, we consider two systems (Visa and MasterCard, say). All our results carry over if the systems' users (member banks) face competition from nonmembers (outside issuers, such as American Express). ${ }^{3}$ Systems are indexed by $i$ or $j$ in $\{1,2\}$.

Each system engages in innovation. To fix ideas, each system $i$ invests in reducing the members' unit cost $c_{i}$ of servicing a customer (or a transaction). (One may have in mind that both systems start from initial unit cost $c^{0}$ and select $c_{i} \leq c^{0}$.) This process innovation involves investment cost

$$
F\left(c_{i}\right)+f\left(c_{i}\right) x_{i}
$$

for system $i$, where $x_{i}$ is the number of customers (or transactions) on system $i, F$ is a fixed innovation cost, and $f$ is a variable/per-unit innovation cost. $F(\cdot)$ and $f(\cdot)$ are nonincreasing and convex functions. Section 4 considers the case of a proportional cost $(F \equiv 0)$ and the case of a fixed cost $(f \equiv 0)$.

The "not-for-profit" nature of the associations means that any net income is not distributed to owners. In practice, "not-for-profit" entities can earn and accumulate some net income. In our static framework, though, it is natural to assume that the "not-forprofit" systems adopt the cost-recovery objective. ${ }^{4}$

Assumption 1. Systems cover their costs with usage fees.

System $i$ charges a per-unit access charge (or "system fee") $a_{i}$ so as to cover its cost. It does not pay any dividend; neither does it receive lump-sum investment contributions (negative dividends).

We will later discuss the case in which one or both of the systems are for-profit.

Remark. Allowing for product innovations that shift the users' willingness to pay uniformly involves a simple relabelling. Instead of reducing the member banks' unit cost of servicing a customer, the quality of service of a card of type $i$ to the customer is association $i$ 's choice variable. The association can then pursue innovations that increase this quality. Mathematically, the quality of service is just (minus) the bank's per-unit cost in our model. ${ }^{5}$

Issuers. Member banks are indexed by $k$ or $\ell$ in a set $\{1, \ldots, n\}$. The total unit cost of servicing a customer using a system $i$ credit card is $a_{i}+c_{i}$. We assume that issuers can issue cards on either system. Issuer $k$ issues system $i$ 's card at price $p_{i}^{k}{ }^{6}$

\footnotetext{
3 To generalize the analysis, one includes the outside issuers' price vector in the demand functions and proceeds through the same steps.

${ }^{4}$ More generally, credit card associations retain earnings so as to smooth investments and usage fees. The cost-recovery objective is then an intertemporal one.

${ }^{5}$ Our efficiency result does not carry over to quality improvements that do not shift the willingness to pay uniformly. As in the case of a for-profit company (Spence, 1975), the quality selected by the association can be under- or overoptimal. But there is no presumption that duality itself is detrimental to the provision of innovation.

6 We could allow for price discrimination, e.g., by letting issuers issue the same card at different prices to different consumers; but for simplicity, we take the price to be uniform.
} 
Issuers compete for customers. We allow for a very general formulation. In the equilibrium of the issuer competition stage, credit card prices depend on the input costs $\left(a_{1}+c_{1}\right)$ and $\left(a_{2}+c_{2}\right)$. Therefore, let $\pi^{k}\left(a_{1}+c_{1}, a_{2}+c_{2}\right)$ denote issuer $k$ 's overall profit. This reduced form encompasses a variety of situations, in which the issuers are differentiated among themselves, may differ in their efficiency, or else in the number of installedbase customers on each of the systems (in the latter case, one possible interpretation of "customers" in our model is new customers and customers willing to switch issuer). Aggregating over all issuers, let $x_{i}\left(a_{i}+c_{i}, a_{j}+c_{j}\right)$ denote system $i$ 's equilibrium volume. We make the following weak assumption.

Assumption 2. The equilibrium volume of system $i$ credit cards issued is decreasing in card $i$ 's total unit cost, $a_{i}+c_{i}$, for the member banks, and increasing in the rival system's total unit cost, $a_{j}+c_{j}$.

Last, we assume that the members elected to the board of a system (or at least a majority of them) have no incentive to sabotage the system.

Assumption 3. For each system $i \in\{1,2\}$, there exists a majority of board members, such that for each issuer $k$ in this majority,

$$
\frac{\partial\left(\pi^{k}\left(a_{i}+c_{i}, a_{j}+c_{j}\right)\right)}{\partial\left(a_{i}+c_{i}\right)} \leq 0
$$

We will illustrate Assumption 3 later. Let us simply note that Assumption 3 would be expected to hold in most circumstances in which the decision-making bank's card portfolio was weighted toward cards on the relevant system or at least was not weighted too heavily against the system. A decrease in the cost on the relevant system will lead to greater sales of cards on that system and, to some extent, lesser sales of cards on other systems. The decision-making bank will benefit as long as the net effect is positive, as is likely if the bank's portfolio is not weighted too heavily against the relevant system.

\section{Illustration: the double-differentiation model}

- To illustrate competition among issuers, let us assume that the issuers and the systems are differentiated along two distinct product-configuration dimensions, and that the impacts of differentiation are additive; that is, no issuer has a comparative advantage in issuing a card on one system rather than the other. The locations of the systems and issuers are exogenous and fixed; the case of endogenous sytem locations is addressed in Section 5. Given these fixed locations, firms compete in prices (fees). 


\section{6 / THE RAND JOURNAL OF ECONOMICS}

Differentiation between the two systems is as in Hotelling's model: A customer's preferred card brand is located on an interval [0,1]. System 1's card is located at 0 and system 2's card at 1; that is, as in Hotelling, the systems' cards are located at the two extremes of the interval. Customers incur a loss equal to $t$ times the distance between their ideal brand and the brand they select. ${ }^{7,8}$ Thus, a customer located at distance $x_{1}$ from system 1 (and thus distance $x_{2}=1-x_{1}$ from system 2 ) incurs loss $t x_{1}$ or $t\left(1-x_{1}\right.$ ) from choosing card 1 or card 2 , respectively. ${ }^{9}$

Similarly, we assume that the issuers are differentiated as in the Lerner-Salop model. ${ }^{10}$ Customers are located along a circle of length 1 . The two characteristics of a consumer, namely location in the "system space" and location in the "issuer space," are independent. The issuers' locations are equidistant, so the distance between two issuers is $d=1 / n$. (The model converges to one of perfect competition among issuers when $n$ tends to infinity.) The customers' unit "transportation cost" in the issuer space is labelled $u$. Note that we make no assumption on the distribution of customers in either the system space or the issuer space.

Thus, consider a customer located between issuers $k$ and $\ell$ at distance $y$ of issuer $k$ and $d-y$ of issuer $\ell$; let this customer be located in the system space at distance $x_{1}$ of system 1 and $x_{2}=1-x_{1}$ of system 2 . This customer chooses both an issuer and a card marketed by this issuer by solving

$$
\min \left\{u y+\min \left[p_{1}^{k}+t x_{1}, p_{2}^{k}+t x_{2}\right], u(d-y)+\min \left[p_{1}^{\ell}+t x_{1}, p_{2}^{\ell}+t x_{2}\right]\right\}
$$

Given unit costs $a_{1}+c_{1}$ and $a_{2}+c_{2}$ on the two systems, the $n$ issuers wage multiproduct Bertrand competition: Each issuer $k$ chooses a pair of prices $\left\{p_{1}^{k}, p_{2}^{k}\right\}$ that maximizes its profit given the prices chosen by the other issuers.

Proposition 1 below shows that issuers apply the same margin to both cards (i.e., $\left.m^{k}=m_{i}^{k}=p_{i}^{k}-\left(a_{i}+c_{i}\right), i=1,2\right)$. Put differently, issuers offer the equivalent of a "perfect two-part tariff": They charge their perceived marginal cost $\left(a_{i}+c_{i}\right)$ for cards and then an "access fee" $\left(m^{k}\right)$ for the right for the consumer to pick a card at marginal cost. Issuers thereby do not distort consumer choice between the two cards and compete only in the markup dimension.

The intuition goes as follows: If the issuer charges the same margin on both cards, customers' choice between its two cards does not depend on their margins. Thus, the only differentiation between issuers is along the issuer differentiation dimension. If, on the other hand, the issuer charges different margins on the two cards, the issuer is now differentiated for two reasons: its margin(s) and the fact that it is, in some sense, offering consumers a lower-quality product (nonoptimal system choice). The issuer can increase demand for given margins by eliminating this form of differentiation.

7, Consumers optimally pick a single card in this model. In the United States (but much less so in countries like France), many consumers have more than one card. Much of our analysis (but not that of Section 5) carries over to multiple cards per consumer, since it adopts a broad formulation in terms of transactions rather than customers. For example, consumers could have a preferred card that they use most, as well as other cards (say, no-yearly-fee, no-benefit cards) that they hold primarily for reliability reasons.

8 The credit card literature has focused on the one-card-per-cardholder situation, with the exception of Rochet and Tirole (2002b), who allow for "multihoming" across platforms. Multihoming gives rise to interesting steering strategies for competing platforms, which may use reductions in the interchange fee in an attempt to induce merchants to abandon the rival systems.

${ }^{9}$ We focus on differentiation by systems with respect to direct system services to consumers and issuers. Another potential dimension of system differentiation (although not an actual one for Visa and MasterCard) is merchant acceptance. We refer, e.g., to Rochet and Tirole (2002a) and Schmalensee (2002) for analyses of interchange fees and merchant acceptance.

10 The Lerner-Salop model is a straightforward generalization of the Hotelling model to more than two firms. See, e.g., Tirole (1988) for more details. 
Proposition 1 (characterization of equilibrium). In the double-differentiation model, it is an equilibrium for all issuers $k \in\{1, \ldots, n\}$ to apply the same margin to both cards:

$$
m^{k}=p_{1}^{k}-\left(a_{1}+c_{1}\right)=p_{2}^{k}-\left(a_{2}+c_{2}\right)
$$

Proof. Consider a customer located at $x_{1} \in[0,1]$ in the system space. Let

$$
C^{*}\left(x_{1}\right) \equiv \min \left\{a_{1}+c_{1}+t x_{1}, a_{2}+c_{2}+t\left(1-x_{1}\right)\right\}
$$

denote the minimum cost for the customer when credit cards are sold at the issuers' total marginal cost $\left(a_{i}+c_{i}\right)$.

Suppose that customers can purchase card $i$ from issuer $\ell(\ell \neq k)$ at price $a_{i}+c_{i}+m^{\ell}$, that is, issuer $\ell$ applies a uniform markup. A customer located at $x_{1}$ in the system space and at distance $y$ of issuer $k$ and $d-y$ of issuer $\ell$ in the issuer space must compare the total cost of being a customer of issuer $\ell$, namely $u(d-y)+C^{*}\left(x_{1}\right)+m^{\ell}$, and the total cost of being a customer of issuer $k$.

Thus, consider issuer $k$ 's pricing policy given that the other issuers (including $\ell$ ) apply the same markup on both cards (this markup can differ among issuers), and conduct the following thought experiment: Suppose that issuer $k$ knows the customer's preference $\left(x_{1}\right)$ in the system space (but does not know her location in the issuer space); in this thought experiment, issuer $k$ can charge individualized prices $\left\{p_{1}^{k}\left(x_{1}\right), p_{2}^{k}\left(x_{1}\right)\right\}$. This way, we obtain an upper bound on the profit actually made by issuer $k$ on customers located at $x_{1}$ in the system space. We then show that this upper bound can be obtained by issuer $k$ even when it does not know the customer's location $x_{1}$ in the system space.

Suppose that issuer $k$ induces customers located at $x_{1}$ to use card $i$ conditionally on their selecting issuer $k$ (note that this choice does not depend on the customers' location in the issuer space):

$$
p_{i}^{k}\left(x_{1}\right)+t x_{i} \leq p_{j}^{k}\left(x_{1}\right)+t x_{j}
$$

where $\left\{x_{i}=x_{1}, x_{j}=1-x_{1}\right\}$ if $i=1$ and $\left\{x_{i}=1-x_{1}, x_{j}=x_{1}\right\}$ if $i=2$.

Letting $m_{i}^{k}\left(x_{1}\right) \equiv p_{i}^{k}\left(x_{1}\right)-\left(a_{i}+c_{i}\right)$ denote the margin made on customers located at $x_{1}$ by issuer $k$, a customer of type $x_{1}$ and located at distance $y$ of issuer $k$ and $(d-y)$ of issuer $\ell$ prefers issuer $k$ or $\ell$ depending on whether

$$
\begin{gathered}
p_{i}^{k}\left(x_{1}\right)+t x_{i}+u y=\left[a_{i}+c_{i}+t x_{i}\right]+m_{i}^{k}\left(x_{1}\right)+u y \\
\gtrless C^{*}\left(x_{1}\right)+m^{\ell}+u(d-y) .
\end{gathered}
$$

From this comparison and $a_{i}+c_{i}+t x_{i} \geq C^{*}\left(x_{1}\right)$, we conclude that issuer $k$, for a given markup, maximizes its market share among customers located at $x_{1}$ in the system space by offering such customers the card that is most appropriate to them: $a_{i}+c_{i}+t x_{i}=C^{*}\left(x_{1}\right)$. But this efficient allocation is obtained precisely by setting the same markup on both cards. Furthermore, because for $a_{i}+c_{i}+t x_{i}=C^{*}\left(x_{1}\right), x_{1}$ no longer plays a role in the comparison above (this is where we use the assumption that the other issuers apply the same margin to both cards). Thus, the optimal markup $m^{k}$ for issuer $k$ is independent of $x_{1}$, which implies that the upper bound on bank $k$ 's profit is reached even when the bank does not know the customer's location in the system space. Q.E.D. 


\section{8 / THE RAND JOURNAL OF ECONOMICS}

Robustness of Proposition 1. Proposition 1 is driven by the assumption that no issuer has a comparative advantage in issuing a card on one system rather than the other. Given this assumption, the result is very general: We have made no assumption on the distribution of consumers in the system or issuer spaces. Nonlinear "transportation costs" would not alter the results. Last, the differentiation among issuers could be vertical rather than horizontal; that is, an issuer would offer a service that all consumers would agree is superior to the service offered by a rival issuer. ${ }^{11}$ And Proposition 1 does not rely on the symmetry assumptions imposed on the differentiation spaces.

We establish the next proposition for the case of uniformly distributed customers, although this distributional assumption is stronger than necessary.

Proposition 2 (uniqueness). Assume that customers are uniformly distributed in system space and issuer space. Then, the double-differentiation model admits a unique equilibrium, namely that described in Proposition 1.

Proof. See the Appendix.

Last, we investigate whether the double-differentiation model satisfies the general assumptions made in Section 2. First, consider Assumption 2, according to which the volume of system $i$ cards is decreasing in card $i$ 's total unit cost, $a_{i}+c_{i}$, and increasing in card $j$ 's total unit cost, $a_{j}+c_{j}$. Because consumers face the same margin on both cards, when buying from a given issuer, everything is as if the cards were sold at marginal cost as far as the choice between the two cards is concerned. Hence, more consumers choose card $i$ over card $j$ if $a_{i}+c_{i}$ decreases or if $a_{j}+c_{j}$ increases.

Second, consider Assumption 3. In the basic double-differentiation model described above, the issuers' profits are independent of system marginal costs and therefore Assumption 3 is satisfied trivially, although with weak inequalities (cost decreases are fully competed away).

It is straightforward to generalize the double-differentiation model so that issuers strictly benefit from reductions in system marginal costs, but the treatment and Propositions 1 and 2 are unchanged. Let us next consider two such generalizations.

Installed base customers. Suppose that issuer $k$ services $z_{1}^{k}$ and $z_{2}^{k}$ installed base customers under long-term contracts or lock-in effects, for example. Then, the cost of servicing these customers is $z_{1}^{k}\left(a_{1}+c_{1}\right)+z_{2}^{k}\left(a_{2}+c_{2}\right)$. Hence, competition for new customers is as before, but issuers strictly prefer system marginal costs to decrease.

Outside options. Another reason why issuers may benefit from lower system costs is that the associations' card payments do not exhaust the set of actual payments. That is, the two associations face competition from other issuers (e.g., American Express or Discover) or from alternative means of payments (e.g., cash or checks). Then, even though issuers associated with the two systems compete away system cost reductions in their competition among themselves, they still gain from these reductions because the associations gain market share against other means of payment.

11 The result also extends to issuer differentiation models in which, unlike the Lerner-Salop model, issuers compete directly with more than two "neighbors." 
This "demand-augmentation" feature can be formalized in the following simple way: ${ }^{12}$ Suppose that consumers are ex ante identical. At "search" or "discovery" cost $s$, to be interpreted as a transaction cost, they can learn about fees as well as what type of preference they actually have with respect to systems and issuers. That is, they learn their exact location in the issuer and system spaces, as described above. Let $v$ denote the gross surplus of using a card, from which must be subtracted transportation costs and fees. So an individual with discovery cost $s$ envisions getting a card if and only if

$$
s \leq v-E_{(x, y)}\left[\min _{\{k, i\}}\left\{a_{i}+c_{i}+m^{*}+t\left|x-x_{i}\right|+u\left|y-y^{k}\right|\right\}\right]
$$

(consumers have rational expectations about the equilibrium margin $m^{*}$ charged by issuers). Suppose now that the cumulative distribution of $s$ in the population is given by $G(s)$. Let $s^{*}$ satisfy (2) with equality. The number of cardholders is then $G\left(s^{*}\right)$. The analysis of issuer competition is completely unchanged, but the number of consumers using cards increases as either system's cost decreases, since $s^{*}$ is a decreasing function of $a_{1}+c_{1}$ and $a_{2}+c_{2}$. We therefore conclude that with outside options, issuers are strictly better off when system costs decrease.

Proposition 3. (i) Assumption 2 is satisfied: The volume of system $i$ credit cards is decreasing in card $i$ 's total unit cost, $a_{i}+c_{i}$, and increasing in card $j$ 's total unit cost, $a_{j}+c_{j}$.

(ii) All issuers are better off when the total unit cost of either system decreases; they are strictly better off provided that

(a) either some customers do not purchase cards from either system (outside option model),

(b) and/or the issuers service some installed base customers on that system.

Then, Assumption 3 is satisfied.

\section{Production efficiency}

- Proportional system cost. In this subsection, we assume that system $i$ 's total cost is

$$
f\left(c_{i}\right) x_{i}
$$

Because the associations cover their cost,

$$
a_{i}=f\left(c_{i}\right) .
$$

The timing has two stages. In period 1 (the investment stage), the associations choose $c_{i}$ resulting in total system unit cost $a_{i}+c_{i}$. In period 2 (the production stage), issuers choose their prices $\left\{p_{1}^{k}, p_{2}^{k}\right\}$ under duality and $\left\{p_{i(k)}^{k}\right\}$ under exclusivity (where $i(k)$ is issuer $k$ 's system).

Duality. Under duality, issuer $k$ 's profit is

$$
\pi^{k}\left(f\left(c_{1}\right)+c_{1}, f\left(c_{2}\right)+c_{2}\right) .
$$

Assumption 3 immediately yields the following.

12 An alternative would be to index consumers by three types or characteristics: their preferences relative to systems and to issuers (as in the double-differentiation model) as well as their preferences for alternative means of payment. The formulation adopted here is simpler. 


\section{0 / THE RAND JOURNAL OF ECONOMICS}

Proposition 4. Under proportional system cost and under proportionate (usage-based) fees, association $i$ selects the cost-minimizing technology, that is, the one that solves

$$
\min _{c_{i}}\left\{f\left(c_{i}\right)+c_{i}\right\}
$$

It is important to understand why the optimal innovation result obtained here differs from the results of the "underinvestment" literature in which firms choose to underinvest in cost saving so as to soften second-stage price competition. The difference arises because of the not-for-profit nature of the associations and the way in which the investment expenses of the associations are paid. The association uses usage fees to cover its investment expenses. The usage fee acts as a tax on members. As such, the incentive to underinvest is eliminated.

Let us see how the relaxation of either institutional feature (not-for-profit, usagebased fees) affects the efficiency result. First, suppose that the systems were run as for-profit corporations and had market power. The usage-based fee (the tax) would then in general not be set at the right level. The not-for-profit setup leads to efficiency by solving the "double-marginalization" problem that would exist in a for-profit setup.

Second, if instead of usage fees a lump-sum payment were required of members, underinvestment would be likely to occur. The reason for this is that innovations tend to be competed away through competition among the members unless the latter pay a variable charge for use of the systems. To take an extreme example, consider the doubledifferentiation model of Section 3 and assume that the entire credit card market (or more generally the means-of-payment market) is covered by Visa and MasterCard. In this case, the gross profits $\pi^{k}\left(c_{1}, c_{2}\right)$ (which do not depend on the variable access charges, since $a_{1}=a_{2}=0$ under lump-sum contributions) are independent of $c_{1}$ and $c_{2}$ because the demand for an issuer's cards then depends only on the price differential (that is, on the margin differential) and not on the common costs of using the two systems. And because the lump-sum contributions to investment increase with the levels of cost reduction, the issuers' net profits decrease strictly with investments. Hence, the associations undertake no investment! To be sure, the case in which the entire market is covered by Visa and MasterCard is unrealistic. The members of these associations face competition from other issuers such as American Express, and from cash and checks. The associations then may have some incentive to invest in innovation in order to gain market share against other credit cards and means of payment, even when they are financed through investment grants by the members. But this incentive in general will be suboptimal because some of the gains from investment are competed away through competition among the members. (The latter informal claims could be discussed more rigorously using the outside-options extension in Section 3.)

A similar point concerning underinvestment under lump-sum contributions is made by Guerin-Calvert and Ordover (1998), who pursue it further to argue that duality reduces investment. In their model, the end of duality leads to issuers splitting between systems 1 and 2 . They show that investment by the associations is higher in the absence of duality; the intuition is that under exclusivity, the members of each association do not internalize the negative impact of their investment on the members of the other association. They therefore have more incentive to invest than under duality. These results, however, are contingent on the issuers' each paying a lump-sum grant to the association(s) to which they belong; ${ }^{13}$ in contrast, when investment costs are recovered through proportionate (usage-based) fees, then investment is efficient under either duality or exclusivity.

\footnotetext{
${ }^{13}$ In Guerin-Calvert and Ordover, each member pays $1 / \mathrm{n}$ of the investment cost, where $n$ is the number of members of the association.
} 
Remark. The same logic as that of Proposition 4 shows that a not-for-profit association's rational board members (maximizing their own profit) vote for not earning any net income, given that this income cannot be redistributed (because leaving a net income is equivalent to investing inefficiently). So the cost-coverage assumption (Assumption 1) can be replaced by the broader assumption that associations are not-for-profit.

Exclusivity. As discussed in Section 1, the question has arisen as to whether the board of a given association should be populated only by banks that exclusively issue cards of that association (the banks not sitting on any board being able to issue cards of both associations). We leave aside the issue of whether a bank would be willing to give up one of its products to serve on an association's board, ${ }^{14}$ by assuming that both member and board dualities are repealed. Thus, all issuers now have an exclusive relationship with a single system (generalized exclusivity). The elimination of duality a priori may affect investment choices and product diversity.

Production efficiency. Let us begin with the former. It is straightforward to see that the elimination of duality has no impact on investment choices, as long as an issuer's profit decreases with its system's cost:

Proposition 5. Under proportional system cost, association $i$ selects the cost-minimizing technology, that is, the one that solves

$$
\min _{c_{i}}\left\{f\left(c_{i}\right)+c_{i}\right\} .
$$

That is, production efficiency obtains under exclusivity as well as under duality.

Product variety. Let us next investigate the product variety implications of exclusivity. As we will point out, these implications are likely to be minor in the current context of the credit card industry. But because the framework will be useful for other contexts or other industries, we lay out some of the considerations to be accounted for.

The elimination of duality would not have the effect of spinning off to separate ownership one of a given issuer's products (say, its MasterCard), which would then compete with the issuer's Visa product. Instead, the elimination of duality would eliminate the issuer's MasterCard product. ${ }^{15}$ This outcome is equivalent to raising the price of the MasterCard product to its "virtual" level (i.e., the price at which demand for the product would be zero). In the absence of entry of new products or repositioning by remaining products, the elimination of the issuer's MasterCard would lead to the elimination of the consumers' surplus associated with the MasterCard, along with higher prices on remaining products because of the reduced competition. Both of these effects may harm consumers. As new products generally have been found to increase consumer welfare, ${ }^{16}$ so may the removal of the issuer's MasterCard product reduce consumer welfare. Entry or repositioning might reduce the harm to consumers, but as long as the issuer's MasterCard product could not be replicated by an equally attractive product, overall consumer welfare would be reduced.

\footnotetext{
${ }^{14}$ It would be willing only if it derived control benefits from sitting on the board. Discussing this issue therefore requires a broader framework in which the interests of a given system's issuers are not aligned.

15 In the Guerin-Calvert and Ordover (1998) model, there is differentiation between the two systems, but no differentiation among the issuers, who form a Cournot oligopoly. Thus preventing an issuer from issuing a card does not reduce the set of products offered to consumers, while it does so in our model.

16 See, e.g., Hausman (1997). In general, however, one should consider the costs and benefits of product diversity in a particular context. As is well known (e.g., Dixit and Stiglitz, 1977), oligopolistic competition may generate too few or too many products from a social viewpoint.
} 


\section{2 / THE RAND JOURNAL OF ECONOMICS}

To illustrate the impact of exclusivity on consumer allocation and market power, consider the double-differentiation model; maximal issuer differentiation implies that, under exclusivity, the issuers (spaced evenly along the circle) alternate between systems. So the two direct "neighbors" of a member of system 1 are members of system 2, for instance. In this setup, it is instructive to consider two polar cases in which the deadweight loss created by the imposition of exclusivity is small even if the elimination of products is not partly compensated by new entry or repositioning of existing products:

(i) Issuer differentiation is much more substantial than system differentiation $(u \gg t)$. If a given issuer's Visa Card is close to its MasterCard, not much consumer surplus is lost when duality is eliminated.

Assuming (just for the sake of this argument) that consumers are located uniformly along the circle, it is easy to see that the issuers' margin is almost unchanged as each issuer competes with its direct neighbors (which issue a different but very similar system card). Thus, when issuer differentiation dominates, exclusivity has no impact on issuer market power and on the allocation of consumers to issuers; the allocation of consumers to systems is incorrect, ${ }^{17}$ but the cost of misallocation is small.

(ii) System differentiation is much more substantial than issuer differentiation $(t \gg u)$. In this other polar case, each issuer on system $k$ competes with the two members of system $i$ that are closest to it (and therefore located at a distance equal to twice the distance of their direct neighbors). The issuers' margin increases when duality is replaced by exclusivity, but it and the distortion created by holes in the product space remain small, since issuers are little differentiated.

General case. While exclusivity may lead to an incorrect allocation of consumers to systems because of issuer differentiation, and to increased issuer market power under system differentiation, these distortions are small in the two polar cases just described (and probably therefore in the currrent context of the credit card industry in which systems are little differentiated). But they may be nonnegligible in general. Note further that we have assumed system differentiation to be exogenous. Although this may be a fine assumption in some cases, the duality-exclusivity choice affects the extent of system differentiation when the latter is endogenous: see Section 5. Thus, a careful study of product variety must further consider the impact on system differentiation.

Fixed system cost. Let us now assume that the associations incur only fixed costs $F\left(c_{i}\right)$ and no usage-based innovation cost. $F$ is decreasing and convex. The case of a fixed system cost raises complex conceptual as well as practical issues concerning the concept of not-for-profit associations: Suppose that the system commits some up-front investment, presumably financed through a bank loan, and sets a usage-based fee. The system runs the risk of not being able to reimburse its loan if membership turns out to have been forecasted too optimistically. In the presence of uncertainty, the lender de facto has some "equity" in the association. 18

To avoid this issue and to preserve the not-for-profit nature of the association, we assume perfect foresight and the following timing:

Stage 1. The associations choose their investment policy $\left(c_{i}\right.$ for system $\left.i\right)$.

17 Under a uniform distribution of consumers in the system space, about half of the consumers are allocated to the wrong system.

18 Assuming that fixed investment costs are financed through retained earnings from previous years' usage-based fees is an appealing alternative assumption; however, it does not solve the issue, since somehow the system has to get started. Also, financing investment through retained earnings may be inefficient in periods of large investment needs. 
Stage 2. Having observed $\left\{c_{1}, c_{2}\right\}$, the member banks issue cards of the two systems. Let $x_{1}$ and $x_{2}$ denote the number of cards issued (or equivalently the number of transactions). ${ }^{19}$ We assume that the issuers are sufficiently competitive, so that they do not take into account the effect of individual issuer choice on the usage-based fee of each system (they take $a_{i}$ as given).

Stage 3. The associations implement their announced investment policies $\left(c_{i}\right)$ and charge usage-based fees so as to cover their investment cost,

$$
a_{i}=\frac{F\left(c_{i}\right)}{x_{i}} .
$$

The number of cards issued on each system by member banks is a function of the banks' total cost,

$$
\hat{c}_{i} \equiv c_{i}+\frac{F\left(c_{i}\right)}{x_{i}}
$$

of using the systems. (We here use the perfect-foresight assumption by letting member banks at stage 2 anticipate the system fee they will face at stage 3.)

A short discussion of tipping is in order. Not-for-profit associations facing fixed costs of investment are highly exposed to tipping: If other member banks induce their customers to buy/use the other system, then the fixed cost is spread over a smaller number of customers, which induces banks to desert the system. In the following, we will assume away tipping effects and multiple equilibria. ${ }^{20}$ But one should keep in mind that associations are very exposed to such effects. We discuss tipping further in Section 5.

We will say that an allocation is "symmetric" or more precisely "system-symmetric" if $c_{1}=c_{2}$ and $x_{1}=x_{2}$. Such an allocation may (but need not) be issuer-symmetric in that a given issuer's card portfolio may weigh the two systems differently. Letting $x_{i}\left(c_{1}, c_{2}\right)$ denote the volumes as functions of the banks' proportional costs of using the two systems, the equilibrium volumes $\left\{x_{1}, x_{2}\right\}$ are given implicitly by the system of two equations in two unknowns:

$$
x_{i}=X_{i}\left(c_{1}+\frac{F\left(c_{1}\right)}{x_{1}}, c_{2}+\frac{F\left(c_{2}\right)}{x_{2}}\right) .
$$

Our no-tipping approach together with Assumption 2 suggests the following assumption:

Stability assumption.

(i) $\operatorname{sign}\left(\frac{\partial x_{1}}{\partial c_{1}}\right)=-\operatorname{sign}\left(\frac{\partial x_{2}}{\partial c_{1}}\right)=-\operatorname{sign}\left(1+\frac{F^{\prime}\left(c_{1}\right)}{x_{1}}\right)$.

(ii) At a symmetric allocation, $\left|\frac{\partial x_{1}}{\partial c_{1}}\right| \geq\left|\frac{\partial x_{2}}{\partial c_{1}}\right|$.

Part (ii) of this assumption is satisfied by the double-differentiation model of Section 3 with equality if the credit card market is covered, and with strict inequality otherwise.

We now analyze whether cost minimization obtains in various settings.

\footnotetext{
${ }^{19}$ We do not necessarily assume a Cournot game. Rather, and in conformity with the rest of this section, we think of issuers as setting retail prices for cards, which generate volumes $x_{1}$ and $x_{2}$.

${ }^{20}$ One way to justify this assumption is to posit the existence of installed bases, $z_{i}$, so that the usage-based fee becomes $a_{i}=F\left(c_{i}\right) /\left[z_{i}+x_{i}\right]$, and to assume that investment costs are moderate and that switching the installed base to the other system is costly.
} 


\section{4 / THE RAND JOURNAL OF ECONOMICS}

Duality. Suppose first that banks setting $c_{i}$ at stage 1 issue both cards at stage 2, and let us look for a symmetric equilibrium. Bank $k$ sitting on the board of system 1 , say, solves

$$
\max _{c_{1}}\left\{\pi^{k}\left(c_{1}+\frac{F\left(c_{1}\right)}{x_{1}\left(c_{1}, c_{2}\right)}, c_{2}+\frac{F\left(c_{2}\right)}{x_{2}\left(c_{1}, c_{2}\right)}\right)\right\} .
$$

In addition to Assumption 3, we assume that at a symmetric allocation, for the median board member of system $1, \pi_{1}^{k} \leq \pi_{2}^{k}$, where subscripts to $\pi^{k}$ indicate partial derivatives with respect to the first or second argument. Again, this assumption is motivated by the idea that a board member's portfolio is not weighted so heavily against that system as to make him strictly prefer average cost reductions in the other system rather than in the system he is a director of. The total derivative of a board member's profit is

$$
\pi_{1}^{k}\left(1+\frac{F^{\prime}\left(c_{1}\right)}{x_{1}}\right)-\pi_{1}^{k} \frac{F\left(c_{1}\right)}{x_{1}^{2}} \frac{\partial x_{1}}{\partial c_{1}}-\pi_{2}^{k} \frac{F\left(c_{2}\right)}{x_{2}^{2}} \frac{\partial x_{2}}{\partial c_{1}} .
$$

At a symmetric equilibrium, $c_{1}=c_{2}$ and $x_{1}=x_{2}$ :

$$
\operatorname{sign}\left(-\pi_{1}^{k} \frac{F\left(c_{1}\right)}{x_{1}^{2}} \frac{\partial x_{1}}{\partial c_{1}}-\pi_{2}^{k} \frac{F\left(c_{2}\right)}{x_{2}^{2}} \frac{\partial x_{2}}{\partial c_{1}}\right)=-\operatorname{sign}\left(1+\frac{F^{\prime}\left(c_{1}\right)}{x_{1}}\right) .
$$

To see this, note that stability assumptions (i) and (ii) together with $\pi_{1}^{k} \leq 0$ and $\pi_{1}^{k} \leq \pi_{2}^{k}$ yield the conclusion. For example, suppose that $\left[1+\left(F^{\prime} / x_{1}\right)\right]<0$. Then $-\pi_{1}^{k}\left(\partial x_{1} / \partial c_{1}\right)>0$. Either $\pi_{2}^{k} \geq 0$ and then the sum of the two terms within the bracket is positive, or $\pi_{2}^{k}<0$; but then $\left|\pi_{1}^{k}\right| \geq\left|\pi_{2}^{k}\right|$ together with stability assumption (ii) implies that the second term is dominated. The same reasoning holds if $\left[1+\left(F^{\prime} / x_{1}\right)\right]>0$. Therefore, the sign of the total derivative is the opposite of the sign of $\left[1+\left(F^{\prime} / x_{1}\right)\right]$. The first-order condition for optimality on each system is therefore

$$
1+\frac{F^{\prime}\left(c_{i}\right)}{x_{i}}=0
$$

That is, cost minimization obtains. ${ }^{21}$ Note that our assumptions ruling out tipping are more restrictive than necessary for the productive efficiency result to hold. In particular, one could have productive efficiency even in a tipping equilibrium.

Exclusivity. Suppose now that banks sitting on the board of a system can't issue credit cards on the other system. This situation includes both the polar case of exclusivity (no bank is allowed to issue both cards) or partial exclusivity (banks sitting on a board cannot issue cards on the other system, but other banks can issue both cards). It is still the case that the number of cards issued depends on the total unit costs $\hat{c}_{1}$ and $\hat{c}_{2}$ on the two systems. We again look for a symmetric equilibrium (again, by "symmetric" we mean "system symmetric"). There are two departures from the duality case.

First, the profit of an issuer $k$ sitting on the board of system 1, say, increases with $\hat{c}_{2}$ (while it decreases with $\hat{c}_{2}$ under duality in the double-differentiation model, for instance):

$$
\pi_{2}^{k}>0
$$

${ }^{21}$ Unfortunately, it is possible that other tipping equilibria exist that are optimal for issuers but would occur only if a small amount of productive inefficiency were introduced. That is, it is theoretically possible, although not economically plausible, that a bit of productive inefficiency could be used as a "sunspot" in this multiple-equilibrium world to select the desirable equilibrium. Our stability condition, which again is too restrictive, is one way of ruling out such implausible phenomena. 
The proof that the sign of the total derivative of $\pi^{k}$ with respect to $c_{1}$ is that of

$$
1+\frac{F^{\prime}\left(c_{1}\right)}{x_{1}}
$$

holds a fortiori.

Second, the absence of duality, by restricting output, ${ }^{22}$ increases $\hat{c}_{1}=\hat{c}_{2}$. Hence, the investment made by each association is smaller than under duality. We therefore will say that the systems engage in conditional cost minimization: They minimize cost given membership, but because membership is smaller than under duality, investment is correspondingly smaller.

For-profit system(s). Let us now assume that system 1, say, is run by a for-profit corporation, while system 2 is still an association. The for-profit corporation sets both $c_{1}$ and the access fee $a_{1}$ at stage 1 . Let $\widetilde{x}_{1}\left(a_{1}+c_{1}, c_{2}\right)$ denote the volume on system $1 .{ }^{23}$ It solves

$$
\max _{\left\{a_{1}, c_{1}\right\}}\left\{a_{1} \widetilde{x}_{1}\left(a_{1}+c_{1}, c_{2}\right)-F\left(c_{1}\right)\right\} .
$$

The first-order conditions are

$$
x_{1}+a_{1} \frac{\partial \widetilde{x}_{1}}{\partial c_{1}}=0
$$

and

$$
a_{1} \frac{\partial \widetilde{x}_{1}}{\partial c_{1}}=F^{\prime}\left(c_{1}\right)
$$

And so,

$$
1+\frac{F^{\prime}\left(c_{1}\right)}{x_{1}}=0
$$

Again, we obtain conditional cost minimization. The cost is minimized conditionally on the level of $x_{1}$. However, the for-profit system uses its market power to set a high system fee, thus restricting volume. ${ }^{24}$ There is therefore overall underinvestment by the for-profit system, even though its investment is appropriate for the volume generated. The same conclusion would hold if both systems were for-profit.

Proposition 6. Under fixed system cost and the stability assumption,

(i) the systems' investment minimizes cost under duality.

(ii) under exclusivity or for-profit governance, conditional cost minimization obtains: the systems minimize cost conditionally on volume; but because volume is suboptimal, the systems invest less than under duality.

\section{Discussion}

- Our analysis makes a number of assumptions, which we now discuss.

22 Output is restricted because Visa issuers no longer issue MasterCards and, with differentiated products, total output falls with the reduction in the number of products.

${ }^{23}$ Again, $\widetilde{x}_{i}\left(a_{1}+c_{1}, c_{2}\right)$ are given implicitly by the system of two equations with two unknowns:

$$
x_{i}=X_{i}\left(a_{1}+c_{1}, c_{2}+\frac{F\left(c_{2}\right)}{x_{2}}\right) .
$$

${ }^{24}$ In this sense, underinvestment results from double marginalization. 


\section{6 / THE RAND JOURNAL OF ECONOMICS}

System differentiation. While we have allowed systems to offer different qualities to the consumers or cost to the issuers (so we allowed for some vertical differentiation, although no such differentiation arises in symmetric equilibrium), we took the horizontal choice of differentiation as given: see, e.g., the double-differentiation model. Two natural questions then are: Do systems have an incentive to differentiate more horizontally ${ }^{25}$ under exclusivity than under duality? What is the impact of such differentiation on welfare?

We can avail ourselves of little empirical evidence on the former question. Visa and MasterCard are currently little differentiated. Potential vertical differentiation includes availability with merchants, speed and reliability of transactions, and cost to the issuer. Our article addresses the latter two dimensions. With regard to merchant availability, both Visa and MasterCard are available virtually everywhere. So little differentiation is to be expected there. Horizontal differentiation (details of the yearly fee/credit availability/penalties/interest rate package, affinity cards, frequent flyer programs, etc.) is to a large extent left to issuers. In this respect, it would be incorrect to build on the (correct) observation that the Visa and MasterCard systems are less differentiated now than BankAmericard and MasterCharge were in the 1970s to infer that differentiation has decreased; the previous differentiation was along the characteristics of the cards rather than the systems.

Providing a general analysis of horizontal system differentiation is not straightforward, as our model already allows for vertical system differentiation as well as issuer choice of allocation of volume between systems. Yet we can use the doubledifferentiation model with outside options (see Section 3) to obtain some interesting insights as to the relevant tradeoffs.

In this section and solely to simplify the exposition, we assume that the consumers are distributed uniformly on $[0,1]$ in the system space, and we assume that systems noncooperatively choose their locations in the system space so as to maximize the profit of their issuers.

Duality. The proof of Proposition 1 does not rely on the systems' being located at the two extremities of the segment. Therefore (assuming that the market remains covered), the equilibrium margins and profits per potential cardholder are independent of the systems' location choices. What depends on the systems' location, though, is the size of the card market. The number of cardholders $\left(G\left(s^{*}\right)\right.$ in the notation of Section 3$)$ is increasing with the expected adequacy of card offers to satisfy consumers' needs. The expected "transportation cost" along the system dimension is minimized when

$$
x_{1}=\frac{1}{4} \quad \text { and } \quad x_{2}=\frac{3}{4}
$$

That is, each system is located in the middle of its natural constituency. These locations prevail under duality even if the systems choose their locations noncooperatively, which is what we assume here: If system 2 selects $x_{2}=3 / 4$, then all issuers, and therefore those sitting on the board of system 1 , prefer $x_{1}=1 / 4$ so as to get the broadest possible market. $^{26}$

25 The analysis below is couched in Section 3's horizontal differentiation framework. Much of it applies to vertical differentiation choices as well.

${ }^{26}$ So the systems are differentiated under duality, and the extent is half the potential differentiation. Of course, how much differentiation actually takes place depends on the initial scope for differentiation. See above for a discussion of this in the case of credit cards. 
Exclusivity. Under exclusivity, issuers use system differentiation to differentiate themselves. In equilibrium, issuers $k=1,3, \ldots, 2 \ell+1, \ldots$ choose system 1 , while issuers $k=2,4, \ldots, 2 \ell+2, \ldots$ choose system 2 . There is then a strong incentive for system differentiation when the issuers are themselves quite competitive. Indeed, when the unit transportation cost, in the issuer space, $u$, is small, it may be optimal for the issuers to maximally differentiate the systems. The competitive analysis is complex in general and is left for future research. The case of two closely competing issuers is, however, transparent: when $u=0$, the issuers' only differentiation is their systems' differentiation, and we know from d'Aspremont, Gabszewicz, and Thisse (1979) that the issuers strictly prefer to maximally differentiate:

$$
x_{1}=0 \quad \text { and } \quad x_{2}=1 .
$$

By continuity, the same is true for small issuer differentiation.

We summarize our analysis in the following proposition.

Proposition 7 (system differentiation). In the double-differentiation model with uniformly distributed consumers in the system space:

(i) Under duality, system differentiation does not allow issuers to differentiate. Systems noncooperatively choose the socially optimal differentiation, namely half the maximal differentiation $\left(x_{1}=1 / 4, x_{2}=3 / 4\right)$.

(ii) Under exclusivity, system differentiation creates issuer differentiation. With two issuers, systems maximally differentiate $\left(x_{1}=0, x_{2}=1\right)$ as long as these issuers are little differentiated in the issuer space.

Let us conclude this subsection with two points. First, part (i) of Proposition 7 is quite general. In particular, the social optimality of system location in the outside option model of Section 3 does not depend on a uniform distribution of consumers, since (a) issuers' profit is proportional to an issuer-differentiation-determined markup and to the size of credit card demand, and (b) this size is maximized in the outside-option model by minimizing the average transportation cost in the issuer space. ${ }^{27}$ In contrast, part (ii) of Proposition 7 may rely heavily on the two-issuer, small-differentiation assumption. In particular, suppose that the issuers are (almost) local monopolies. Then, system differentiation does little to increase issuer differentiation, and it is in the interest of a system's members to have the system locate in the middle of the segment $\left(x_{1}=x_{2}=.5\right)$ so as to be able to charge higher prices to the consumers.

Second, issuer differentiation may not be independent of system differentiation. Indeed, the two types of differentiation may well be substitutes. It might then be that issuers have more incentive to differentiate along the issuer dimension under duality, since duality prevents issuer differentiation through system differentiation. We leave these two fascinating topics for future research.

$\square \quad$ Prevention of wasteful competition. Sections 3 and 4 consider situations in which each system selects its cost or quality in the absence of direct externalities on the other system. Let us briefly investigate the impact of duality when such externalities exist. Intuitively, boards populated by banks issuing both cards have stronger incentives to prevent self-serving actions by a system that benefits the system but hurts the member banks overall.

${ }^{27}$ For a more general outside-option model, though, the optimality of system differentiation under duality would depend on the assumption of the distribution of consumers. 


\section{8 / THE RAND JOURNAL OF ECONOMICS}

To start with a simple (although extreme) example, suppose that system 1 can take an action that increases the cost $\hat{c}_{2}$ for banks of using system 2 but does not affect (or hardly affects) the cost or quality of system 1 . Such an action might not be taken under duality because the members of the board of system 1 could (like members of board 2) suffer from it. On the other hand, under exclusivity or a for-profit system 1, this action would be more likely to be taken.

Moving to less extreme examples, one may have in mind actions that are designed more to harm the other system than to improve the efficiency of one's own system: e.g., choice of incompatible computer or terminal systems by a dominant association, wasteful advertising, me-too entry in specific segments, refusal to cooperate on joint investments by the two systems, wasteful interchange fee competition, etc.

Agency considerations. We have assumed that the board of a system perfectly controls its decision making. However, an association such as Visa or MasterCard, like any firm, is run by managers. The members would like to set up institutional arrangements that cause the managers' interests to be aligned with their own. But accomplishing such an alignment is a complex matter in ordinary corporations and is even more so in notfor-profit associations. The members of a not-for-profit organization have fewer means by which to create the correct incentives for managers. For instance, the management of a not-for-profit organization cannot be given stock-based compensation, a method widely used in for-profit corporations. Similarly, control by the capital market (a takeover or a proxy fight) is infeasible for not-for-profit associations.

One method members of not-for-profit associations use is relative performance evaluation, in which the performance of the association is compared to the performance of the other association. Such benchmarking may (and does) occur in two ways. First, objective performance measures (such as system market share) may be compared and serve as a basis for managerial compensation. Second, other, less precise information about comparative managerial entrepreneurship could be used.

An interesting question for this article is how duality affects benchmarking. Let us briefly argue that duality does affect benchmarking and may alleviate or intensify the agency problem. ${ }^{28}$

Market-share-based incentive compensation. Duality makes it easy and low cost for a member to switch between systems at the margin. ${ }^{29}$ In this respect, it is important to note that it is less costly for an issuer to induce a new customer to take a card of one system than to move an installed base customer from the other system to this one. The ability to switch systems provides the "punishment" for managers who perform poorly. Duality may provide a "collective choice" mechanism under which issuers can "vote" with their feet. Therefore, system market shares are more sensitive to differences in quality between the two systems under duality than exclusivity, as long as the differences are small enough that issuers do not consider shifting their entire portfolio (new customers and installed base) to a single system. In contrast, for large differentials in system quality, system market shares are more sensitive to differences in quality under exclusivity, since an issuer may be content to move only the new consumers under duality and is tempted to move the entire portfolio of consumers under exclusivity. We conclude that duality facilitates benchmarking for incremental innovations and inhibits benchmarking for large ones.

${ }^{28}$ Further analysis is available upon request from the authors.

${ }^{29}$ As an example of switching at the margin, Citibank recently began putting its new customers on MasterCard instead of Visa. 
Information leakages. Suppose there are aspects of an association's performance that are observable only by members of the association, e.g., non-fee-related costs for the member banks of operating on the association's system. Such "quality" parameters are not easily observable by nonmembers (fees, on the other hand, presumably are easily observable by nonmembers). In this case, duality facilitates relative evaluation of performance along the quality dimension. Only by being a member of both associations can an issuer compare the two associations' performance. For instance, a large Visa issuer who is also familiar with the MasterCard operation can more easily assess the quality of the Visa system. Easier benchmarking obviously facilitates the alignment of managerial interests with those of member banks.

This "benchmark monitoring" can also be a factor at the board level. Board members can more easily assess the performance of the system's management and therefore make more informed decisions as to whether to retain the current team.

Remark. Duality-enhanced benchmark monitoring by the members and the board also affects the speed of diffusion of innovation, a result that has both costs and benefits. For example, a bank sitting on the board of a system may be informed about the other system's superior practice earlier than would be the case, were it not an issuer of the other card. Diffusion benefits issuers and consumers because it reduces cost or increases quality of the imitating system. However, a greater speed of diffusion has a negative impact on the benefit of an innovation for a system's managers. That is, its increase in market share is more transient. This has no effect on incentives as long as incentives are based on career concerns. After all, what matters for reputational purposes is who innovated first, and copying by the other system does not reduce the credit that is obtained by the early innovator's management. Note in this respect that one can have very intense system competition and yet, due to rapid diffusion, very little permanent system differentiation. Thus, one cannot infer from a lack of system differentiation that the systems do not compete. In contrast, rapid diffusion is bad for incentives if incentives are derived from explicit market-share-based compensation schemes.

Tipping. In the presence of large fixed costs, tipping can be a serious issue. There is a large literature on multiple equilibria and tipping in markets with network externalities, and we have nothing to add to this literature concerning equilibrium selection. What we can offer in this respect is more limited: some insights as to when duality may encourage or limit tipping. Let us sum up our previous observations concerning tipping and add a few others. We identify four factors influencing the impact of duality on tipping:

(i) Consumers' demand for diversity. If systems are horizontally differentiated, then some consumers prefer to be affiliated with one system and other consumers prefer the other system. This creates a force in favor of more stability under duality (by "more stability" we mean that the set of parameters under which tipping is an equilibrium is smaller). This force is clearly identified in the unrealistic but instructive case of "local monopolies." That is, suppose that issuers hardly compete with each other (say, they are in different geographic markets). Then, even if much of the overall issuing is done on system 1, a given issuer may still want to issue some cards on system 2. Doing so is less costly to the issuer under duality than under exclusivity, since under exclusivity, the issuer's entire card portfolio must be allocated to the high-cost system 2. So, consumers' demand for system diversity makes tipping less likely under duality. 
(ii) Issuers' willingness to differentiate through system differentiation. As discussed above, issuers cannot differentiate as easily through system differentiation if they belong to the same systems, i.e., if duality exists, as they could under exclusivity. Even under duality, however, directly competing issuers (e.g., neighbors in the double-differentiation model) can differentiate from each other through system differentiation by allocating customers to different systems. This effect may create a force toward less tipping under exclusivity. Consider for example an industry with only two issuers: Under exclusivity, if issuer 1 issues all its cards on system 1, issuer 2 is better off issuing all its cards on system 2 rather than issuing all of them on system 1 . In both cases, neither issuer has a cost advantage, but the issuers gain from differentiation in the former case. In contrast, tipping may occur under duality. The analysis when issuers are "atomistic" vis-à-vis their system (i.e., when an individual issuer's volume does not significantly affect system cost) is complex, and we leave it for future research.

(iii) Installed bases and switching cost. We saw above that duality has an ambiguous impact on tipping when issuers have installed bases for which they must incur switching costs for changing cards/systems. For a small cost or quality differential between the two systems, duality increases system market share sensitivity by allowing issuers to switch "at the margin." This effect per se induces more tipping under duality. On the other hand, when the cost or quality differential is larger, issuers switch their entire portfolios (including their installed bases), and so exclusivity creates more tipping.

(iv) Diffusion of best practice. If, as argued above, member and board duality induces a quicker diffusion of best practices (perhaps at the cost of increased agency problems), then duality makes associations more stable.

We therefore conclude that the impact of duality on tipping is a priori quite ambiguous. Multiple effects are in play, and conclusions are likely to be industry specific and need further empirical investigation. ${ }^{30}$

Other applications and directions for future research. Although we have focused on the credit card industry in this article, the framework has applicability to questions that arise outside of that industry. We point out two areas where our framework can be usefully applied. We conclude by identifying a question for future research for which our model could provide a starting point.

\footnotetext{
${ }^{30}$ A different issue is the desirability of tipping. Tipping is costly for consumer diversity if systems are differentiated. In the presence of large fixed costs, tipping reduces the duplication of fixed costs in the long run, but it also results in monopoly, with an adverse impact on agency costs (see the benchmarking discussion above).
} 
The first area of applicability for our framework is other industries that have the same type of organizational structure we have analyzed here. For example, each of the major equity option exchanges is a not-for-profit membership organization governed by a board populated with members of the exchange (as well as public representatives). ${ }^{31}$ These exchanges finance their activities largely through usage-based fees. A given trading firm can be a member of more than one exchange, and, indeed, many trading firms were members of multiple exchanges. Thus, there exists what we have called member duality. ${ }^{32}$ Furthermore, the exchanges have no rules preventing a member of the board of governors of one exchange from also being a member of other exchanges, so that there also exists what we have called board duality. Thus, our approach could readily be applied to study questions regarding the option exchanges.

Second, our framework can provide guidance in making regulatory policy decisions in industries with cooperatives. An example is the area of business-to-business ("B2B") exchanges. A B2B exchange typically consists of a joint venture among competitors in an industry to develop a web site used principally for the sale of the industry's products or for the purchase of inputs. ${ }^{33}$ Use of the web site is generally not limited to the exchange's owners. A question that has been considered by antitrust regulators is whether an exchange should be allowed to require its owners to conduct all of their business on the exchange. In other words, should exclusivity be allowed or, alternatively, should regulators, by prohibiting exclusivity, de facto impose duality? Our framework suggests that regulators might want to consider the joint imposition of duality along with not-for-profit status. We have demonstrated that this type of organization can lead to more efficient outcomes than cooperatives with a for-profit status. Of course, the specific facts of the case at hand need to be carefully considered as well.

Finally, we point out an interesting direction for future research that emerges from the current article. As noted above, some cooperatives, such as the credit card associations and the equity option exchanges, have chosen to organize as not-for-profit associations with duality. Other cooperatives, such as the B2B exchanges and ATM networks, have chosen to organize as for-profit corporations. Some cooperatives switch between one form and the other. For example, the commodity option exchanges NYMEX and CME have recently decided to convert from not-for-profit associations to for-profit corporations. Our framework demonstrates how a cooperative organized as a not-for-profit association with duality can lead to relatively efficient outcomes. A question for future research is why industry participants would choose to organize their cooperative in this form as opposed to the for-profit form or vice versa. Our framework provides a starting point from which to study this question.

31 The option exchanges are the Chicago Board Options Exchange (CBOE), the American Stock Exchange (AMEX), the Pacific Exchange (PACX), and the Philadelphia Stock Exchange (PHLX)). In the case of AMEX, PACX, and PHLX, the membership organization governs a stock exchange in addition to the option exchange.

32 The practice of "option exclusivity" (whereby options on a given security were traded on a single exchange), which has been the subject of recent antitrust scrutiny, is unrelated to the concept of member exclusivity that we address in this article.

${ }^{33} \mathrm{~B} 2 \mathrm{~B}$ exchanges are just the "new economy" update to the older form of commerce exchanges. 


\section{Appendix}

- Proof of Proposition 2. Index the systems by $i, j \in\{1,2\}$ and issuers by $h, k, \ell \in\{1, \ldots, n\}$. Let $m_{i}^{k}$ denote the margin applied to card $i$ by issuer $k\left(m_{i}^{k}=p_{i}^{k}-a_{i}-c_{i}\right)$. Suppose that there is at least one (issuer, system) pair for which the margin strictly exceeds $u d$. Without loss of generality, suppose that the pair with the highest margin is composed of system 1 and issuer $k$, who thus applies $m_{1}^{k} \geq m_{2}^{k}$ and $m_{1}^{k} \geq m_{1}^{\ell}$ for all $\ell$. (If there is no (issuer, system) pair for which the margin exceeds $u d$, but there is at least one (issuer, system) pair for which the margin is strictly lower than $u d$, perform the same reasoning with the (issuer, system) pair with the lowest margin $m_{1}^{k}$, say, and consider a small increase in $m_{1}^{k}$ instead of a small decrease in $m_{1}^{k}$, as we do below.)

Let us assume for the moment that issuer $k$ sells both cards and competes directly with its neighbors $h$ and $\ell$ in equilibrium, as depicted in Figure A1.

Pure interbrand competition (e.g., card 1 sold by $h$ or $k$ ) gives rise to vertical separating lines as in Hotelling's model. Similarly, pure intrabrand competition (e.g., cards 1 and 2 sold by $k$ ) gives rise to horizontal separating lines. Mixed inter/intrabrand competition (e.g., card 1 sold by $h$ against card 2 sold by $k$ ) provides the other separating lines.

A small decrease in $m_{1}^{k}$ has two first-order effects: it expands the $(k, 1)$ region eastward and westward to the detriment of competitors $h$ and $\ell$, and it cannibalizes sales of $(k, 2)$ southward. Let $X_{1}^{k}$ and $X_{2}^{k}$ denote issuer $k$ 's sales on systems 1 and 2 . Then issuer $k$ 's profit is

$$
\pi^{k}=m_{1}^{k} X_{1}^{k}+m_{2}^{k} X_{2}^{k}
$$

Consider a small decrease $d m_{1}^{k}=-\eta$, leading to $d X_{1}^{k}=\varepsilon_{1}^{k}+\varepsilon_{2}^{k}$ and $d X_{2}^{k}=-\varepsilon_{2}^{k}$, where $\varepsilon_{1}^{k}, \varepsilon_{2}^{k}, \eta>0$. $\varepsilon_{2}^{k}$ corresponds to the cannibalization effect, while $\varepsilon_{1}^{k}$ corresponds to consumers stolen from issuers $h$ and $\ell$. The variation in issuer $k$ 's profit is

$$
d \pi^{k}=\left[-X_{1}^{k} \eta+m_{1}^{k} \varepsilon_{1}^{k}\right]+\left[m_{1}^{k}-m_{2}^{k}\right] \varepsilon_{2}^{k} .
$$

Let us consider the first effect (interbrand allocation). Using equation (1) in the text, the sign of the firm term in the expression of $d \pi^{k}$ can be obtained by taking the derivative of issuer $k$ 's profit keeping $x_{1}$ constant. Issuer $k$ 's profit on system 1 cards $m_{1}^{k} X_{1}^{k}$ is ( $x_{1}$ times)

$$
m_{1}^{k}\left[d+\frac{m_{1}^{h}-m_{1}^{k}}{2 u}+\frac{m_{1}^{\ell}-m_{1}^{k}}{2 u}\right] .
$$

The optimal reaction therefore satisfies

$$
\left[m_{1}^{k}-u d\right]=\frac{\left[m_{1}^{h}-u d\right]+\left[m_{1}^{\ell}-u d\right]}{4} .
$$

From this, we conclude that issuer $k$ should apply a margin $m_{1}^{k}<\max \left(m_{1}^{h}, m_{1}^{\ell}\right)$. (To show this, recall that $m_{1}^{k}-u d \geq \max \left\{m_{1}^{h}-u d, m_{1}^{\ell}-u d\right\}$ and so $m_{1}^{k}-u d \geq\left\{\left[m_{1}^{h}-u d\right]+\left[m_{1}^{\ell}-u d\right]\right\} / 2$. Now, if the righthand side of this latter inequality is strictly positive, then the inequality is satisfied with strict inequality when the "2" is replaced by a " 4 ," which conflicts with the optimal reaction described above. Or, the right-hand side is equal to zero or negative, and again we obtain a contradiction relative to the optimal reaction.) So the interbrand effect on $k$ 's profit of reducing $m_{1}^{k}$ is strictly positive: $-X_{1}^{k} \eta+m_{1}^{k} \varepsilon_{1}^{k}>0$.

But there is a second effect, as we saw. The "cannibalization" or "intrabrand" effect shifts $x_{1}$. This effect on $k$ 's profit is positive because it reallocates $k$ 's consumers to the high-margin card $\left(m_{1}^{k} \geq m_{2}^{k}\right)$. This is the term $\left[m_{1}^{k}-m_{2}^{k}\right] \varepsilon_{2}^{k} \geq 0$ in the expression of $d \pi^{k}$. Hence, we do get a contradiction.

This reasoning seemingly assumes that each of the six (issuer, card) pairs commands positive sales. It can be shown that the same reasoning applies when $k$ sells none of a given system's card or when $k$ competes with further-away cards (e.g., $k$ 's neighbor on the left applies a very high margin on card 1 and so does not sell card 1). Q.E.D.

\section{References}

D'Aspremont, C., Gabszewicz, J., and Thisse, J.-F. "On Hotelling's 'Stability in Competition.' " Econometrica, Vol. 17 (1979), pp. 1145-1151.

Dixit, A.K. And Stiglitz, J.E. "Monopolistic Competition and Optimum Product Diversity." American Economic Review, Vol. 67 (1977), pp. 297-308.

Evans, D.S. and Schmalensee, R.L. Paying with Plastic: The Digital Revolution in Paying and Borrowing. Cambridge, Mass.: MIT Press, 1999. 
Guerin-Calvert, M. and Ordover, J. "Maximizing Current and Future Network Competition in Payment Systems." Paper presented at the 34th Annual Conference on Bank Structure and Competition, Chicago, 1998.

Hansmann, H. The Ownership of Enterprise. Cambridge, Mass.: Belknap Press, 1996.

Hausman, J. "Valuation of New Goods Under Perfect and Imperfect Competition." In T.F. Bresnahan and R. Gordon, eds., The Economics of New Goods. Chicago: University of Chicago Press, 1997.

Rochet, J.-C. And Tirole, J. "Cooperation Among Competitors: Some Economics of Payment Card Associations." RAND Journal of Economics, Vol. 33 (2002a), pp. xxx-xxx.

__ _ AND _ _ _. "Platform Competition in Two-Sided Markets." Mimeo, IDEI, University of Toulouse, 2002b.

Schmalensee, R. "Payment Systems and Interchange Fees." Journal of Industrial Economics, Vol. 50 (2002), pp. 103-122.

Spence, A.M. "Monopoly, Quality, and Regulation." Bell Journal of Economics, Vol. 6 (1975), pp. $417-429$.

Tirole, J. The Theory of Industrial Organization. Cambridge, Mass.: MIT Press, 1988. 